\title{
Low risk of late post-traumatic seizures following severe head injury: implications for clinical trials of prophylaxis
}

\author{
JUDITH K McQUEEN, DHR BLACKWOOD, P HARRIS, RM KALBAG, AL JOHNSON
}

SUMMARY A randomised, controlled, double-blind clinical trial designed to determine the effectiveness of phenytoin in preventing epilepsy in patients who had suffered a serious head injury is reported. One hundred and sixty-four patients were randomly assigned to treatment with phenytoin or placebo capsules for one year. Patients who had a fit within one week of injury were excluded. Drug levels were monitored throughout with appropriate dosage adjustment; however only $48 \%$ of the phenytoin group had plasma levels greater than $40 \mu \mathrm{mol} / \mathrm{l}$. There were seven deaths during the study. Only 11 patients (six in the phenytoin group and five in the placebo group) developed post-traumatic epilepsy within one year; a further four patients developed seizures between 1 and 2 years after injury. This low incidence of post-traumatic epilepsy (7\% (SE $2 \%$ ) at one year and $10 \%$ (SE $2 \%$ ) at two years) means that future clinical trials of prophylaxis will have to be much larger (at least six fold).

The effectiveness of anticonvulsant drugs in the prevention of epilepsy after head trauma remains controversial. Phenytoin appears to have some prophylactic effect in focal cortical epilepsy in animals. ${ }^{1-4}$ However, Rapport and Penry, ${ }^{5}$ in a review of post-traumatic epilepsy prophylaxis in man reported an absence of adequate controlled clinical trials on which to base clear guide-lines for treatment. Servit and Musil ${ }^{6}$ claimed that a regime of phenytoin (160-240 $\mathrm{mg}$ daily) in combination with phenobarbitone (30-60 $\mathrm{mg}$ daily) provided effective prophylaxis of post-traumatic epilepsy, which persisted throughout the follow-up period of 8-13

Report of the Edinburgh/Newcastle Head Injury Study Group. Participants: Judith K McQueen and DHR Blackwood (Trial Co-Ordinators), MRC Brain Metabolism Unit, Department of Pharmacology, Edinburgh; AL Johnson (Statistician), MRC Biostatistics Unit, Medical Research Council Centre; Cambridge; $P$ Harris (Trial Director), FJ Gillingham, ER Hitchcock, JF Shaw, AJW Steers, V Brezinova, Department of Surgical Neurology, Western General Hospital, Edinburgh; RM Kalbag, MJ Betty, AJ Strong, Department of Neurological Surgery, Newcastle General Hospital, Newcastle; A Irvine, Pharmacy, Edinburgh Royal Infirmary.

Address for reprint requests: JK McQueen, University Dept of Phamacology, 1 George Sq, Edinburgh EH8 9J2, UK.

Received 31 March 1982 and in revised form 7 May 1983. Accepted 14 May 1983 years. Penry and co-workers, using a similar therapeutic regimen were unable to confirm these findings. ${ }^{7}$ A prophylactic effect of phenytoin alone has been reported in two studies which used retrospective controls. ${ }^{89}$ More recently, in a controlled, prospective study Young et al $^{1011}$ have claimed that phenytoin is ineffective in preventing early or late post-traumatic seizures.

The results reported here were derived from a randomised, controlled, double-blind clinical trial designed to compare phenytoin and placebo prophylaxis following head injury in patients considered at high risk of post-traumatic epilepsy. Treatment policies consisted of randomly allocated phenytoin or placebo prophylaxis for one year after trial entry, followed by withdrawal of treatment from all seizure-free patients and continued follow-up for a second year. A preliminary report based mainly upon the first year of follow-up of each patient was given at the XIIth Epilepsy International Symposium..$^{12}$ In view of the low incidence of late onset post-traumatic epilepsy found in this study we present here results from the combined treatment series (phenytoin and placebo) following completion of two-year follow-up; we present an estimate of the risk of late onset post-traumatic epilepsy following severe head injury and discuss the resultant implications for future clinical trials of prophylaxis. 


\section{Methods}

Patients All patients, aged between 5 and 65 years who had suffered a head injury and were admitted to either the Department of Surgical Neurology at Edinburgh Royal Infirmary (from 1 Janurary 1977) or the Department of Neurological Surgery at Newcastle General Hospital (from 1 November 1977) were eligible for entry to the trial provided that the injury was complicated by one of the following features: dural penetration, intracranial haematoma (extradural, subdural or intracerebral), depressed skull fracture (bone depressed at least the thickness of the cranium), persistent neurological deficit (more extensive than cranial nerve injury alone) or post-traumatic amnesia (PTA) for more than 24 hours after injury. These criteria, either alone or in combination, may be associated with an increased risk of post-traumatic epilepsy. ${ }^{13}$ Patients with a history of epilepsy (other than febrile convulsions in infancy) before injury, or who developed epilepsy in the first week after injury (early post-traumatic epilepsy) were excluded. The nature of the trial was explained to the patient, or a relative, and the patient entered in the trial only if (signed) informed consent was given.

Phenytoin or placebo treatment was administered by the hospital pharmacist using a prepared list of random treatment allocations. Capsules of $50 \mathrm{mg}$ or $100 \mathrm{mg}$ phenytoin and matched placebo capsules (both supplied by WarnerLambert (UK) Ltd) were prescribed on the day of admission to the trial. In children (5-15 years inclusive) the initial daily dose was $5 \mathrm{mg} / \mathrm{kg}$ body weight; for adults $300 \mathrm{mg}$ as a single or divided daily dose was prescribed. The trial was conducted "double-blind" with prescribed treatment known only to the hospital pharmacy and the trial coordinators, who had no responsibility for patient care and follow-up.

Patients were seen at an out-patient clinic at 2 weeks after discharge from hospital and at $6,12,15,18$, and 24 months after head injury. Enquiries about seizures were made to the family doctors of the few patients who persistently failed to attend out-patient clinics. Follow-up after 24 months was achieved through routine neurological clinic attendances and family doctor enquiry. During the first year of follow-up drug dosage was adjusted to achieve "optimal" therapeutic concentration of phenytoin (40 to $80 \mu \mathrm{mol} / \mathrm{l}$ ); changes of capsules were also recommended for patients on placebo to preserve the double-blind design of the trial. At one year after injury phenytoin or placebo capsules were withdrawn over a two week period.

Patients were withdrawn from the trial after the development of epilepsy, which was diagnosed from the history obtained from patients, their relatives, general practioners and hospital staff. For this trial, epilepsy was diagnosed on clinical features alone; EEG changes, though looked for, were not a prerequisite. All patients with suspected epilepsy were seen by a consultant neurologist before a final diagnosis was made. The date of the fit was taken as the date of withdrawal from the trial, and patients withdrawn were followed-up for the occurrence of further seizures.

Statistics The period (in weeks) from randomisation to either the date of first seizure, death or the last date seizure-free was calculated for each patient. Actuarial percentage seizure-free curves (life-table) were calculated for the separate treament groups and the combined series. Using information on the first two years of follow-up only, the hazard rate for late onset post-traumatic epilepsy was calculated using the maximum likelihood estimator for progressively censored data assuming an exponential distribution of times to first post-traumatic seizure ${ }^{14}$ this assumption was checked by assessing linearity in a plot of time to first seizure against cumulative hazard rates. An approximate $95 \%$ confidence interval for the true hazard rate was calculated using the "quick" estimate. ${ }^{14}$ The reported power calculations are based upon the logrank test. $^{15}$

\section{Results}

During the 35 months when patients were admitted to the trial 5032 patients with head injury were admitted to the Department of Surgical Neurology in Edinburgh. Of these $103(2.0 \%)$ had a seizure within 1 week of head injury and were not eligible for entry to this trial. This estimate of the incidence of early epilepsy agrees closely with that of Annegers et al. ${ }^{16}$

Only $118(2.4 \%)$ patients satisfied the criteria for severe head injury and were admitted to the trial. The most common cause of head injury in the Edinburgh patients was involvement in a road traffic accident $(48 \%)$; sports injuries, accidents in the home or at work, and assault, accounted for approximately equal proportions of the remainder. Entry to the trial stopped in October 1979 when 164 patients had been recruited. Their distributions by sex, age gioup, centre and the period between injury and trial entry are shown in table 1.

The distribution of patients by admission criteria is shown in table 2. Fifty-four per cent of the patients entered satisfied at least two of the admission criteria and $67 \%(50 / 75)$ of those satisfying just one criterion had features associated with severe head injury other than PTA greater than 24 hours. Consequently at least $85 \%(139 / 164)$ of the patients entered in this trial had injuries associated with a high risk of post-traumatic epilepsy. ${ }^{13} 17$

Compliance to the trial protocol was assessed both from the numbers of prescriptions dispensed and by monitoring the plasma concentrations of phenytoin. To encourage compliance, patients were usually advised to take their phenytoin capsules twice daily. Allowing for the patients who died or developed post-traumatic epilepsy $80 \%$ were dispensed capsules for up to 6 months treatment, $68 \%$ for up to 9 months treatment and $49 \%$ for up to 12 months treatment. Therefore, despite regular outpatient appointments and postal reminders, only half of the patients who had initially agreed to enter 
Table 1 Distribution of patients by sex, age group, centre and period between injury and entry to trial

\begin{tabular}{llll} 
& Phenytoin & Placebo & Total \\
\hline $\begin{array}{l}\text { Sex } \\
\text { Male }\end{array}$ & $67(80)$ & $63(79)$ & $130(79)$ \\
Female & $17(20)$ & $17(21)$ & $34(21)$ \\
Age group & & & \\
$5-15$ & $29(35)$ & $14(18)$ & $43(26)$ \\
$16-29$ & $33(39)$ & $34(42)$ & $67(41)$ \\
$30-49$ & $15(18)$ & $19(24)$ & $20(12)$ \\
$50-65$ & $7(8)$ & $13(16)$ & \\
Centre & & & \\
Edinburgh & $59(70)$ & $59(74)$ & $118(72)$ \\
Newcastle & $25(30)$ & $21(26)$ & $46(28)$ \\
Period: injury-entry (days) & & & \\
$<8$ & $19(23)$ & $19(24)$ & $38(23)$ \\
$8-10$ & $23(27)$ & $12(15)$ & $35(21)$ \\
$11-14$ & $18(21)$ & $9(26)$ & $19(12)$ \\
$15-19$ & $12(14)$ & $10(13)$ & $11(7)$ \\
$20-30$ & $2(2)$ & $9(11)$ & 164 \\
\hline 30 & 84 & 80 & \\
Total & & &
\end{tabular}

(Figures in parentheses are percentages of corresponding column totals)

Table 2 Distribution of patients by trial entry criteria

\begin{tabular}{lllr}
\hline & Phenytoin & Placebo & Total \\
\hline Admission criteria & & & \\
Dural penetration & $16(19)$ & $16(20)$ & $32(20)$ \\
Intra-cranial haematoma & $22(26)$ & $22(28)$ & $44(27)$ \\
$\quad$ Extra dural & $13(15)$ & $7(9)$ & $20(12)$ \\
$\quad$ Sub dural & $8(10)$ & $10(12)$ & $18(11)$ \\
$\quad$ Intra-cerebral & $2(2)$ & $6(8)$ & $62(5)$ \\
Depressed skull fracture & $33(39)$ & $39(36)$ & $66(40)$ \\
Persistent neurological deficit & $33(39)$ & $37(46)$ & $78(48)$ \\
PTA for 24 hours & $41(49)$ & & $75(46)$ \\
Number of criteria satisfied & & $37(46)$ & $63(38)$ \\
$1^{*}$ & $38(45)$ & $31(39)$ & $21(13)$ \\
3 & $32(38)$ & $9(11)$ & $5(3)$ \\
4 & $12(14)$ & $3(4)$ & 164 \\
\hline
\end{tabular}

(Figures in parentheses are percentages of corresponding column totals)

* 25 patients (12 phenytoin, 13 placebo) had PTA for 24 hours alone.

the trial persisted with the drug treatment for the full year. A similar degree of non-compliance was suggested by the plasma levels of phenytoin. Only $48 \%$ of the patients in the phenytoin group achieved plasma concentrations greater than $40 \mu \mathrm{mol} / \mathrm{l}$ on at least one occasion; in some patients the therapeutic level was not maintained throughout the 12 months. Thirty-six per cent had concentrations in the range 20 to $39 \mu \mathrm{mol} / 1,12 \%$ in the range 10 to $19 \mu \mathrm{mol} / \mathrm{l}$ and $4 \%$ never had concentrations above $9 \mu \mathrm{mol} / \mathrm{l}$.

The status of all patients 24 months after entry to the trial is shown in table 3 . Only two patients did not complete their scheduled follow-up; both migrated from the Edinburgh area and could not be traced. For the remaining 162 patients two-year follow-up information was complete. Seven patients died with 7 weeks of admission to the trial. The causes of death were heart disease (4), pulmonary embolism (2) and white cell dyscrasia (1). Skin rashes developed in six patients including one in the placebo group. Fifteen patients $(9.1 \%$ of those entered) developed post-traumatic epilepsy within 24 months of injury; details are presented in table 4. Eleven of these patients had several seizures and were still receiving treatment with anticonvulsants two years after injury. In two of the four patients reported to have only single seizures an effect of benzodiazepines or alcohol was implicated. No seizures were reported during the two week withdrawal period from phenytoin at 12 months. No seizures 
Table 3 Status of patients at 24 months after entry to trial and actuarial percentages seizure-free at 6 month intervals

\begin{tabular}{|c|c|c|c|c|c|c|c|c|c|}
\hline \multicolumn{6}{|c|}{ Status at $24 m$ ths after entry } & \multicolumn{4}{|c|}{ Actuarial percentages seizure-free (SE) } \\
\hline $\begin{array}{l}\text { Treatment } \\
\text { Group }\end{array}$ & $\begin{array}{l}\text { Entered } \\
\text { in trial }\end{array}$ & Lost & Died & $\begin{array}{l}\text { Seizure- } \\
\text { free }\end{array}$ & Seizures & $6 \mathrm{mths}$ & 12 mths & 18 mths & 24 mths \\
\hline $\begin{array}{l}\text { Phenytoin } \\
\text { Placebo }\end{array}$ & $\begin{array}{l}84 \\
80\end{array}$ & $\begin{array}{l}2^{*} \\
0\end{array}$ & $\begin{array}{l}5 \\
2\end{array}$ & $\begin{array}{l}69 \\
71\end{array}$ & $\begin{array}{l}8 \\
7\end{array}$ & $\begin{array}{l}97 \cdot 4(1 \cdot 8) \\
96 \cdot 2(2 \cdot 2)\end{array}$ & $\begin{array}{l}92 \cdot 3(3 \cdot 0) \\
93 \cdot 6(2 \cdot 8)\end{array}$ & $\begin{array}{l}92 \cdot 3(3 \cdot 0) \\
93 \cdot 6(2 \cdot 8)\end{array}$ & $\begin{array}{l}89 \cdot 7(3 \cdot 5) \\
91 \cdot 1(3 \cdot 2)\end{array}$ \\
\hline Total & 164 & $2^{*}$ & 7 & 140 & 15 & $96 \cdot 8(1.4)$ & $93 \cdot 0(2 \cdot 0)$ & $93.0(2 \cdot 0)$ & $90 \cdot 4(2 \cdot 4)$ \\
\hline
\end{tabular}

*One patient lost to follow-up on discharge from hospital one week after entry; the other migrated from the Edinburgh area after 78 weeks of follow-up and could not be traced.

Table 4 Patients who developed post-traumatic epilepsy

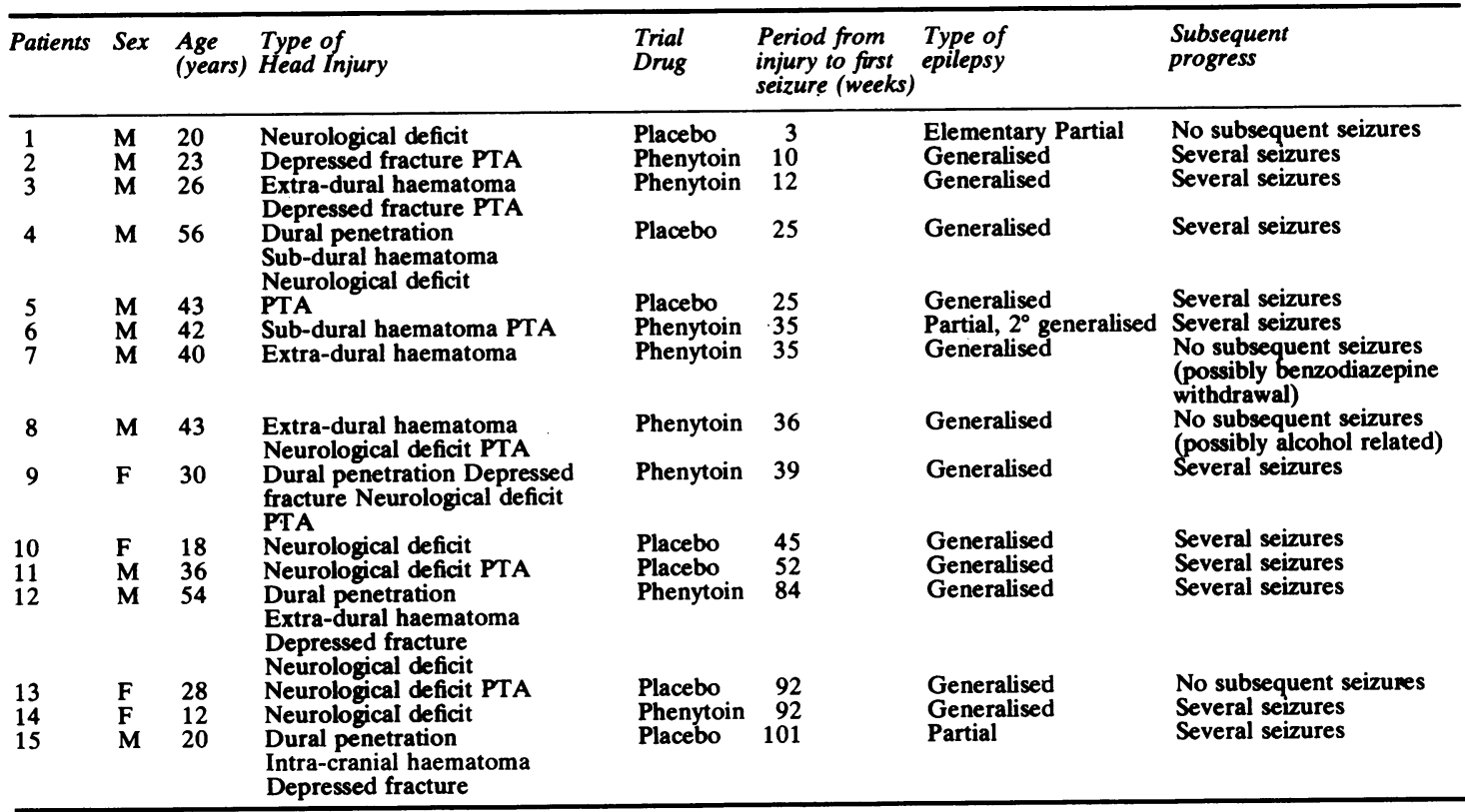

have been reported during further follow-up in the 104 patients who were seizure-free 24 months after trial entry. ( 32 have now been followed-up for 30 months, 21 for 36 months and 13 for over 42 months).

Actuarial percentages seizure-free at six-monthly intervals up to two years from entry are also presented in table 3 . The occurrence of seizures in only 15 patients gives an overall actuarial seizure-free rate of $90.4 \%$ at 24 months (with $95 \%$ confidence limits at $85.8 \%$ and $95.0 \%$ ). If the 25 patients who presented with prolonged PTA only are excluded from the analysis on the grounds that they may have suffered only minor injury, then the overall actuarial seizure-free rate at 24 months remains almost unaltered at $89.5 \%$ (with $95 \%$ confidence limits at $84.9 \%$ and $94.7 \%$ ).

Assuming that the times from entry to first post- traumatic seizure are exponentially distributed the estimated resultant constant hazard rate (here the probability that a patient develops post-traumatic epilepsy within the next week given that he started the week seizure-free) over the 24 month follow-up period is $0.00098 /$ week (with $95 \%$ confidence limits at $0.00048 /$ week and $0.0015 /$ week).

\section{Discussion}

The number of cases of post-traumatic epilepsy in this sample of 164 patients is not high enough to permit any conclusions to be drawn on the effectiveness of phenytoin used prophylactically after head injury. These prospective findings do, however, give a reliable estimate of the risk of post-traumatic seizures which is considerably lower than that reported in much earlier studies, ${ }^{13}$ but which is in agreement 
with results form prospective studies reported recently. ${ }^{11} 16$ Annegers et $^{16}{ }^{16}$ reviewed a population of 2747 patients with head injuries served by the Mayo Clinic over a 40-year period and found that the risk of post traumatic seizures after severe head injury was $7.1 \%$ in one year and $11.5 \%$ in five years. Severe injury was defined as brain contusion, intracranial haematoma or 24-hours unconsciousness; these criteria are similar to those used in our study. The exclusion from the present study of patients with early epilepsy may have led to an underestimate of the risk of late onset seizures since the occurrence of fits in the first week after injury increases the risk of late epilepsy. ${ }^{13}$ Patients with early epilepsy were excluded from this study on ethical grounds as it was not considered justifiable to allocate these patients to placebo treatment. A further reason for considering these patients in a separate category is their heterogeneity, since drug and alcohol withdrawal, rather then head injury may account for some of the fits observed during the first few days after hospital admission. A study of alcohol involvement in patients attending the Casualty Department of Edinburgh Royal Infirmary during the period of this trial, revealed that of 37 consecutive cases of head injury referred 19 had a blood alcohol concentration exceeding $80 \mathrm{mg} \%$. $^{18}$

Patients who are symptom-free might be expected to comply less well in taking anticonvulsant medication than patients who have experienced seizures. However, our findings are broadly in agreement with those from studies on out-patients with epilepsy, where poor compliance has been found to be a major cause of low or fluctuating phenytoin levels and inadequate seizures control. ${ }^{19-21}$ Compliance can be improved among epileptic patients if a simplified dosage regime ${ }^{22}$ and frequent clinic visits $^{23}$ are employed. Both strategies were adopted in this study with apparently only limited success. This suggests that in any large trial of epilepsy prophylaxis a low rate of compliance should be anticipated, with perhaps only half the patients taking medication as instructed for the full year.

Our results have considerable implications for clinical trials of anticonvulsant prophylaxis following serious head injury. If it is assumed that $90 \%$ of patients who do not have seizures within the first week of injury are seizure-free 2 years later without antiepileptic treatment then a clinical trial of prophylaxis must include about 1200 patients to have a $90 \%$ power of detecting (at $p=0.05$ ) a change to at least $95 \%$ seizure-free with anticonvulsant treatment. If it is assumed instead that the two-year seizure-free rate untreated is $85 \%$ (corresponding to the lower $95 \%$ confidence limit of our estimate) then about 1900 patients are required to detect a difference of at least $5 \%$ in seizure-free rate on antiepileptic prophylaxis (with $90 \%$ power at $\mathrm{p}=$ 0.05 ). Differences greater than $5 \%$ between 2 year seizure-free rates in untreated patients and patients given antiepileptic prophylaxis appear unlikely. These results imply that all randomised clinical trials of prophylaxis of late onset post-traumatic epilepsy conducted to date are too small (by a factor of at least six).

The benefits of routine prescription of anticonvulsant drugs in severely head injured patients remains uncertain and the implementation of such a therapeutic policy has to take into account both the high level of non-compliance and the relatively low incidence of post traumatic seizures found in these patients.

We thank the following for their invaluable help during this study: Prof GW Ashcroft, Department of Mental Health, University of Aberdeen: Dr WS Watson, consultant neurologist, Edinburgh Royal Infirmary; Dr G Arbuthnott, MRC Brain Metabolism Unit, Edinburgh; Prof JD Miller, Department of Surgical Neurology, University of Edinburgh; Mr I Fletcher, staff pharmacist, Newcastle General Hospital: Mrs Z Sloanes, Mrs N Brearley, Mrs G Anderson and Mrs C Sarkis, secretaries at Edinburgh Royal Infirmary and the MRC Brain Metabolism Unit; the medical, nursing and ancillary staffs of the neurosurgical units in Edinburgh and Newcastle; and the general practitioners of patients in the study. The financial assistance of Warner-Lambert (UK) Ltd, is gratefully acknowledged.

\section{References}

${ }^{1}$ Lockard JS, Congdon WC, Du Charme LL, Huntsman BJ. Prophylaxis with diphenylhydantoin and phenobarbital in alumina-gel monkey model. Epilepsia 1976;17:37-47.

${ }^{2}$ Morrell F, Bradley W, Ptashne M. Effect of drugs on discharge characteristics of chronic epileptogenic lesions. Neurology (Minneap) 1959;9:492-8.

${ }^{3}$ Racine RJ, Livingston K, Joaquin A. Effects of procaine hydrochloride diazepam and diphenylhydantoin on seizure development in cortical and subcortical structures in rats. Electroencephalogr J Clin Neurophysiol 1975;38:355-65.

4 Rapport RL, Ojemann GA. The effects of prophylactically administered diphenylhydantoin on the development of chronic cobalt-induced epilepsy in the cat. Arch Neurol 1975;32:539-48.

5 Rapport RL, Penry JK. Pharmacologic Prophylaxis of post traumatic epilepsy. Epilepsia 1972;13:295-304.

${ }^{6}$ Servit Z, Musil F. Prophylactic treatment of posttraumatic epilepsy: results of a long-term follow-up in Czechoslovakia. Epilepsia 1981;22:315-20. 
${ }^{7}$ Penry JK, White BG, Brackett CE. A controlled prospective study of the pharmacological prophylaxis of post traumatic epilepsy. Neurology (Minneap) 1979;29:600-1.

${ }^{8}$ Wohns RNW, Wyler AR. Prophylactic phenytoin in severe head injuries. $J$ Neurosurg 1979;51:507-9.

- Young B, Rapp RP, Brooks WH, Madaus W Norton JA. Post traumatic epilepsy prophylaxis. Epilepsia 1979;20:671-81.

${ }^{10}$ Young B, Rapp RP, Norton JA, Haack D, Tibbs PA, Beam JP. Failure of prophylactically administered phenytoin to prevent early post traumatic seizures. $J$ Neurosurg 1983;58:231-5.

1 Young B, Rapp RP, Norton JA, Haack D, Tibbs PA, Bean JR. Failure of prophylactically administered phenytoin to prevent late posttraumatic seizures. $J$ Neurosurg 1983;58:236-41.

12 Blackwood D, McQueen JK, Harris P, et al. A clinical trial of phenytoin in the prophylaxis of epilepsy following head injury: Preliminary report. In: Advances in Epileptology: XIIth Epilepsy International Symposium Dam M, Gram L, JK Penry eds New York: Raven-Press, 1981.

13 Jennett B. Epilepsy after non-missile head injuries. 2nd ed. London: William Heinemann, 1976.

${ }^{14}$ Gross AJ, Clark VA. Survival distributions: reliability applications in the biomedical sciences. London: John Wiley and Sons, 1975.

15 Freedman LS. Tables of the number of patients required in clinical trials using the logrank test. Statistics in Medicine 1982;1:121-9.

${ }^{16}$ Annegers JF, Grabow JD, Groover RV, Laws ER, Elverback LR, Kurland LT. Seizures after head trauma: A population study Neurology (Minneap) 1980;30:683-9.

17 Jennett B, Teasdale G. Management of head injuries. Contemporary Neurology Series Vol 20. Philadelphia: FA Davis Company, 1981.

${ }^{18}$ Holt S, Stewart IC, Dixon JM, Elton RA, Taylor TV, Little K. Alcohol and the emergency service patient. Br Med J 1980;281:638-40.

${ }^{19}$ Gibberd FB, Dunne JF, Handley AJ, Hazleman BL. Supervision of epileptic patients taking phenytoin. $\mathrm{Br}$ Med J 1970;1:147-9.

${ }^{20}$ Kutt H, Haynes J, McDowell F. Some causes of ineffectiveness of diphenylhydantoin. Arch Neurol 1966;14:489-92.

${ }^{21}$ Shorvon SD, Johnson AL, Reynolds EH. Statistical and theoretical considerations in the design of anticonvulsant trials. In: Advances in Epileptology, XIIth Epilepsy International Symposium. Dam M, Gram L, Penry JK. eds New York: Raven Press, 1981.

${ }^{22}$ Terrance $C$, Alberts $M$. Phenytoin dosage in ambulant epileptic patients. J Neurol Neurosurg Psychiatry. 1978;41:463-5.

${ }^{23}$ Wannamaker BB, Morton WA, Gross AJ, Saunders S. Improvement in antiepileptic drug levels following reduction of intervals between clinic visits. Epilepsia 1980;21:155-62. 